\title{
On the application of the Spiegler-Kedem model to forward osmosis
}

\author{
Jun Jie Wu
}

\begin{abstract}
In Forward Osmosis the diffusion of the solute is counter to that of the solvent i.e. there is so-called "reverse salt diffusion". Furthermore, the ratio of the two fluxes is generally taken to be a constant because of the assumption of ideal semi-permeability. However with the Spiegler-Kedem (S-K) model there is an allowance for a minor deviation from ideal semi-permeability and the ratio of the solute flux and solvent flux is no longer constant. The theoretical variation of the solute flux with increasing draw solution concentration is illustrated for various degrees of deviation from ideal semi-permeability. A novel variant of the S-K model is also introduced and predictions compared with those obtained using the standard form. With the acceptance that the form of "breakthrough" involving co-current flow is impossible, a limitation is imposed upon the S-K model but even with this limitation the theoretically predicted variation of solvent flux with increasing draw concentration is for certain sets of parameters of an unexpected form for minor deviation from ideal semi-permeability. That intriguing counter-intuitive outcomes can result from application of the S-K model indicates a need to rethink its formulation of the equations and the expressions for the coefficients. This will have implications for forward osmosis and possibly reverse osmosis modelling.
\end{abstract}

Keywords: Forward osmosis, Spiegler-Kedem model, Reverse osmosis, Pressure-retarded osmosis, Renewable energy

\section{Introduction}

Energy production from the controlled mixing of seawater and fresh water has the advantage that it can be operated continuously unlike processes based on solar and wind energy. The main process in this area and the process that motivated this work is Pressure-Retarded Osmosis (PRO). The pioneers of reverse osmosis recognised the conceptual simplicity of PRO [1] but concern about costs has always been a problem [2-4]. The first pilot plant seeking to develop osmotic energy was opened by the Norwegian energy company Statkraft in 2009 but the pilot plant was closed in 2014 due to the low power density (power per unit of membrane area) exhibited by the prototypes and the questionable economic feasibility of the process [5]. Today it is generally accepted that if PRO is to be commercially viable then it will be necessary to use resources with a higher salinity than seawater, for example brine from a reverse osmosis desalination plant $[6,7]$, but the power output will still be modest. However in a recent purely theoretical paper a thought provoking theoretical analysis by Yaroshchuk

Correspondence: junjie.wu@durham.ac.uk

Department of Engineering, Durham University, Durham DH1 3LE, UK
[8] suggested that under some conditions and with a membrane displaying 'leakiness', a 'breakthrough' mode might occur even to the extent that with the appropriate membranes reverse solute diffusion would be eliminated. Indeed there was the prediction that with these appropriate membranes there would be co-current flow of both solvent and solute against a concentration gradient.

Previous exploration of the implications of the effect of minor deviations from ideal semi-permeability using the Spiegler-Kedem (S-K) model have confined themselves to a single value of the reflection coefficient [8]. In this article a range of values are used. As noted elsewhere [9], whilst irreversible thermodynamic arguments were used to derive the solute and solvent transport equations of the $\mathrm{S}-\mathrm{K}$ model, the membrane itself was treated as a black box". The novel variants of the S-K model introduced here in the context of forward osmosis are not fundamentally based but one form does avoid the incongruity (indeed thermodynamically inappropriateness) arising from the other formulations of the S-K model.

It has been suggested that the total solute flux can change sign, and that the "dramatic change in the 
behaviour is ultimately caused by the change in the direction of solute flow through the membrane" [8]. This specific possibility has been refuted elsewhere where it was also shown (contrary to statements in [8]) that the use of thick support layers is undesirable.

\section{Theory}

Following the S-K equations given in [8], these can be simplified for FO systems by to omitting the pressure term because there should be no overall pressure drop across the barrier layer. The resulting equations are:

$$
\begin{aligned}
& J_{v}=\chi \sigma \cdot \beta R T \frac{d c}{d x} \\
& J_{s}=-\omega \frac{d c}{d x}+(1-\sigma) c J_{v}
\end{aligned}
$$

where $c$ is the reference (virtual) solute concentration (as given in [10] and used in [8]), $\omega$ is the solute permeability, $\sigma$ is the solute reflection coefficient, $J_{s}$ is the solute flux, $J_{v}$ is the solvent flux and $X$ is the hydraulic permeability. $\beta$ is the van't Hoff factor, $R$ the universal gas constant and $T$ the absolute temperature of the system. The implicit assumption in adopting this approach will be discussed later.

Now using Eq. 1 to define $\frac{d c}{d x} / J_{v}$ and substituting the result into Eq.2 it is found that the concentration in the solute flux equation cannot be taken to be a variable because the other terms are all invariant. Consequentially all terms in (3) are fixed.

$$
\frac{J_{s}}{J_{v}}=\frac{-\omega}{X \sigma \beta R T}+(1-\sigma) c
$$

In [8] the concentration $c$ in Eq.2 was a variable but the final term in Eq. 3 would be better written as: $(1-\sigma) c_{i}$ where $c_{i}$ is the concentration of solute at the boundary between the support layer and the barrier layer. Consequently a sounder alternative for the barrier layer would have been:

$$
\frac{B}{A \sigma \beta R T}-(1-\sigma) c_{i}=\left(-\frac{J_{s}}{J_{v}}\right)
$$

where $A$ and $B$ are the standard 'A' parameter and 'B' parameter for water flux and salt flux respectively.

The consequences that follow from the adoption of Eq. 4 are explored below. The layout of the system is illustrated in Fig. 1. For the study of a potential breakthrough mode, this orientation is the one of interest [8]. The arrows show the direction of the actual fluxes but mathematically they are taken as positive in the positive $x$-direction which co-insides with the water flux, $J_{v}$. Hence the set of equations for the support, the barrier layer and the draw side boundary layer are related to each other as follows:

$$
\begin{aligned}
\frac{c_{i} \exp \left(-P e_{s}\right)-c_{f}}{1-\exp \left(-P e_{s}\right)} & =\frac{B}{A \sigma \beta R T}-(1-\sigma) c_{i} \\
& =\frac{c_{d}-c_{m} \exp \left(P e_{b l}\right)}{\exp \left(P e_{b l}\right)-1}=\left(-\frac{J_{s}}{J_{v}}\right)
\end{aligned}
$$

where $P e_{s}$ is the Peclet number for the support layer, $P e_{b l}$ is the Peclet number for the draw-side layer and $c_{m}$ is the concentration at the interface between the membrane and the draw solution. $c_{d}$ is the bulk concentration on the draw side. The external concentration on the feed-side (which is at the low concentration $c_{f}$ ) is insignificant compared with the internal concentration polarisation within the support and a separate term for the mass transfer coefficient on the feed-side has not been included.

As components of Eq. 5 are referred to individually below they are listed out as:

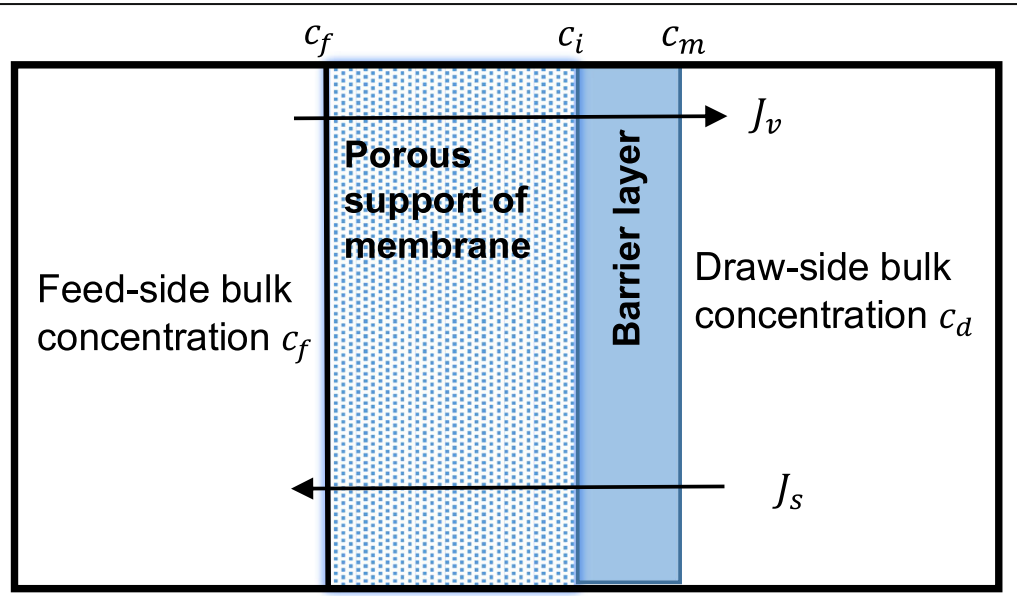

Fig. 1 Schematic of Forward Osmosis system with active layer (barrier layer) facing the draw solution 


$$
\begin{aligned}
& \frac{c_{i} \exp \left(-P e_{s}\right)-c_{f}}{1-\exp \left(-P e_{s}\right)}=\left(-\frac{J_{s}}{J_{v}}\right) \\
& \frac{B}{A \sigma \beta R T}-(1-\sigma) c_{i}=\left(-\frac{J_{s}}{J_{v}}\right) \\
& \frac{c_{d}-c_{m} \exp \left(P e_{b l}\right)}{\exp \left(P e_{b l}\right)-1}=\left(-\frac{J_{s}}{J_{v}}\right)
\end{aligned}
$$

The use of Eq. (4) is consistent with the 'leakiness' giving rise to a convective term that does not vary across the membrane. Initially this paper was going to have an exclusive focus upon exploring (i) the set of equations given by Eq. (5) as an alternative to those in [8]; and (ii) the effect of varying the reflection coefficient. However a new three-parameter model was briefly explored due to increasing concern about the validity of applying the $\mathrm{S}-\mathrm{K}$ model to FO with concentration invariant parameters. Now FO is the simplest of setting for the application of the Spiegler-Kedem model so when this model yields irrational results this indicates that some detail in the S-K model is wrong. This might be the use of concentration invariant parameters. Given an increasing concern about whether the $\mathrm{S}-\mathrm{K}$ model captures the basic physics, a purely empirical equation was developed as an alternative.

Combining Eqs. (1) and (2) one obtains:

$$
J_{s}=-\omega \frac{d c}{d x}+(1-\sigma) c \chi \sigma \cdot \beta R T \frac{d c}{d x}
$$

Now the concentration in the barrier layer at its interface with the draw solution is higher than that at the interface with the support layer and so for constant $J_{s}$ Eq. (6) suggests that $\frac{d c}{d x}$ will vary with position within the membrane (unless $\sigma=1$ ) but the invariant value of the volumetric flux $J_{v}$ with position will via Eq. (1) suggest that $\frac{d c}{d x}$ is constant. There is thus (unless the product of concentration and hydraulic permeability, $c X$ is constant) an apparent contradiction at the heart of the S-K model when it is applied to FO. This point illustrates the cautioning comments given elsewhere [9] and noted above. Furthermore the permeability of salt in polymers is not a constant and for sulfonated polymers, the salt diffusion coefficient increases markedly as the external salt concentration increases [11]. So notwithstanding the established nature of the Spielger-Kedem (S-K) model [12] it should not be seen as so superior as to be above challenge.

An additional reason for asserting that the S-K model, as particularised in [8], is invalid is that it is of the form that one obtains when two resistances are in parallel. If one considers an electrical circuit where there is a current, $I$, flowing through two parallel resistances $\left(R_{1}\right.$ and $R_{2}$ ) driven by a potential difference $V$, then

$$
I=\left(1 / R_{1}+1 / R_{2}\right) V
$$

Comparing Eqs. 6 and 7, the parallels are obvious. However if the second channel associated with $(1-\sigma)$ is considered to consist of pores, the pores will be in contact with the bulk fluids. In reverse osmosis the flow through such channels is sustained by pressure but in FO there is no pressure difference between the two sides and osmosis can only be sustained by perm-selectivity. Whilst there might be a mitigating effect due to convective flow of solvent it is poorly modelled by the above equation. Caution must be taken in the use of the S-K model and it should not be over-interpreted.

The S-K model is a three-parameter model well established for reverse osmosis but rarely used for FO.

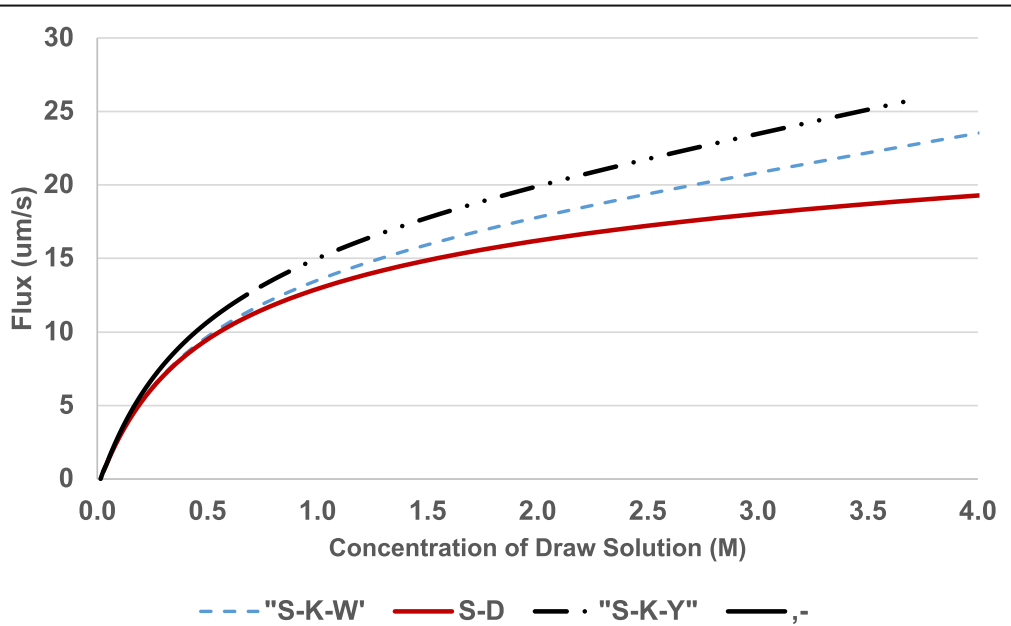

Fig. 2 Predicted influence of draw concentration, $c_{d}$, upon solvent flux, $J_{V^{\prime}}$ for solution-diffusion model and two versions of the Spiegler-Kedem model (S-K-W and S-K-Y). Standard conditions. $\mathrm{A}=10 \mathrm{\mu m} \mathrm{s}^{-1} \mathrm{MPa}^{-1}$ 


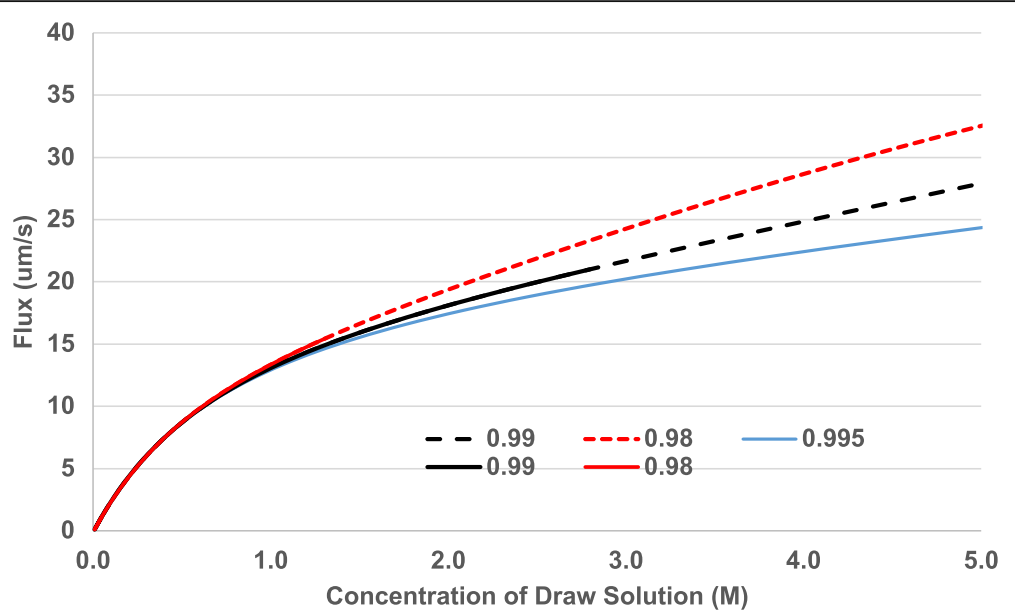

Fig. 3 Predicted influence of draw concentration, $c_{d r}$ upon solvent flux, $J_{v}$ for three different values of the reflection coefficient using the SpieglerKedem model (S-K-W). Dashed curves used for region where co-current fluxes predicted. Standard conditions except $c_{f}=0.005 \mathrm{M}^{\mathrm{A}} \mathrm{A}=6 \mu \mathrm{m} \mathrm{s} \mathrm{s}^{-1} \mathrm{MPa}^{-1}$
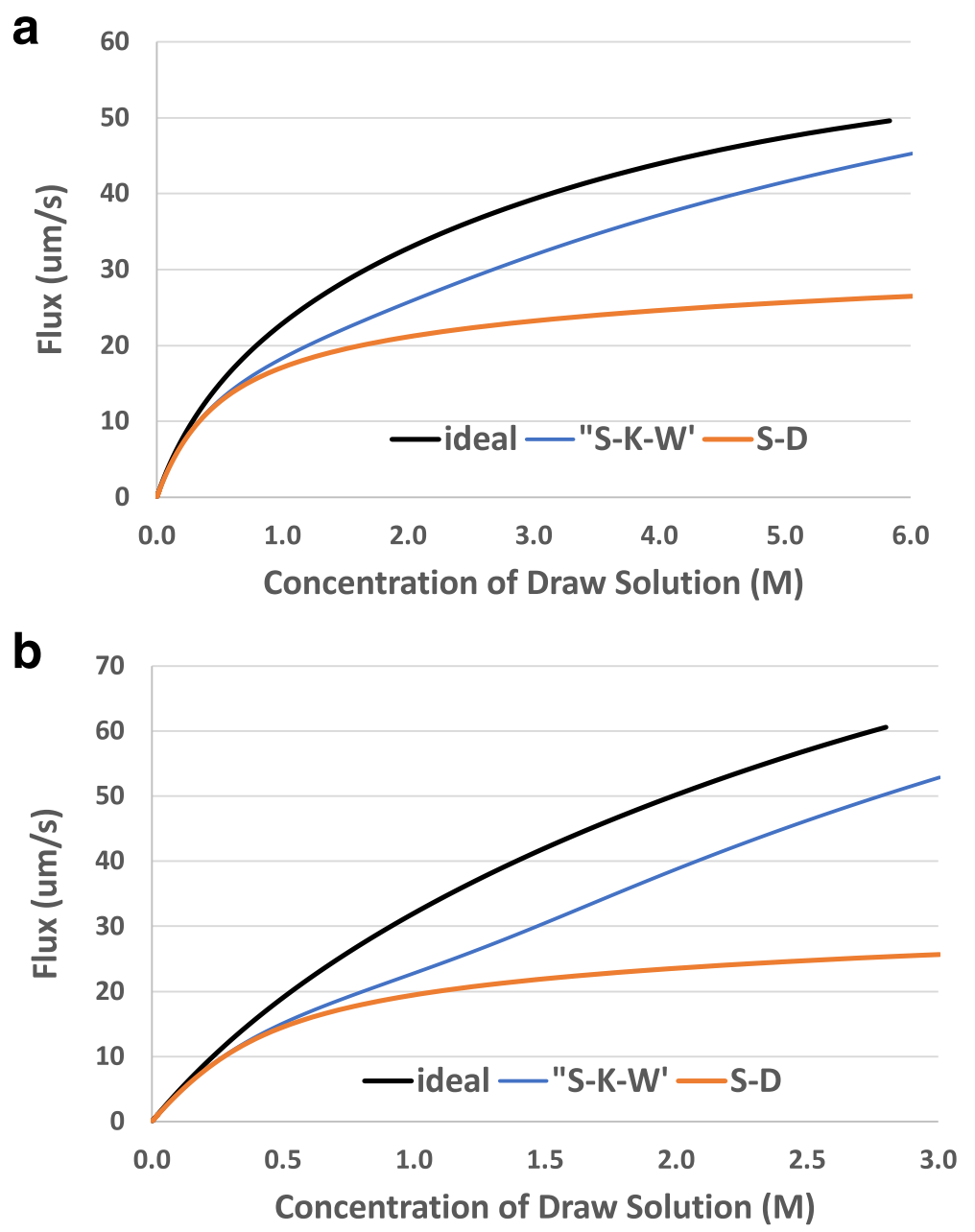

Fig. 4 Solute free feed: Comparison of the predicted influence of draw concentration, $c_{d}$, upon solvent flux, $J_{v}$, for the solution-diffusion model, the solution-diffusion model with $B=0$ (labelled 'ideal') and the Spiegler-Kedem (S-K-W) model with $A=10 \mu \mathrm{m} \mathrm{s}^{-1} \mathrm{MPa}^{-1}$. a Standard conditions except $c_{f}=0$. b Standard conditions except $c_{f}=0$ and $k_{b l}=75 \mu \mathrm{m} \mathrm{s}^{-1}$ 

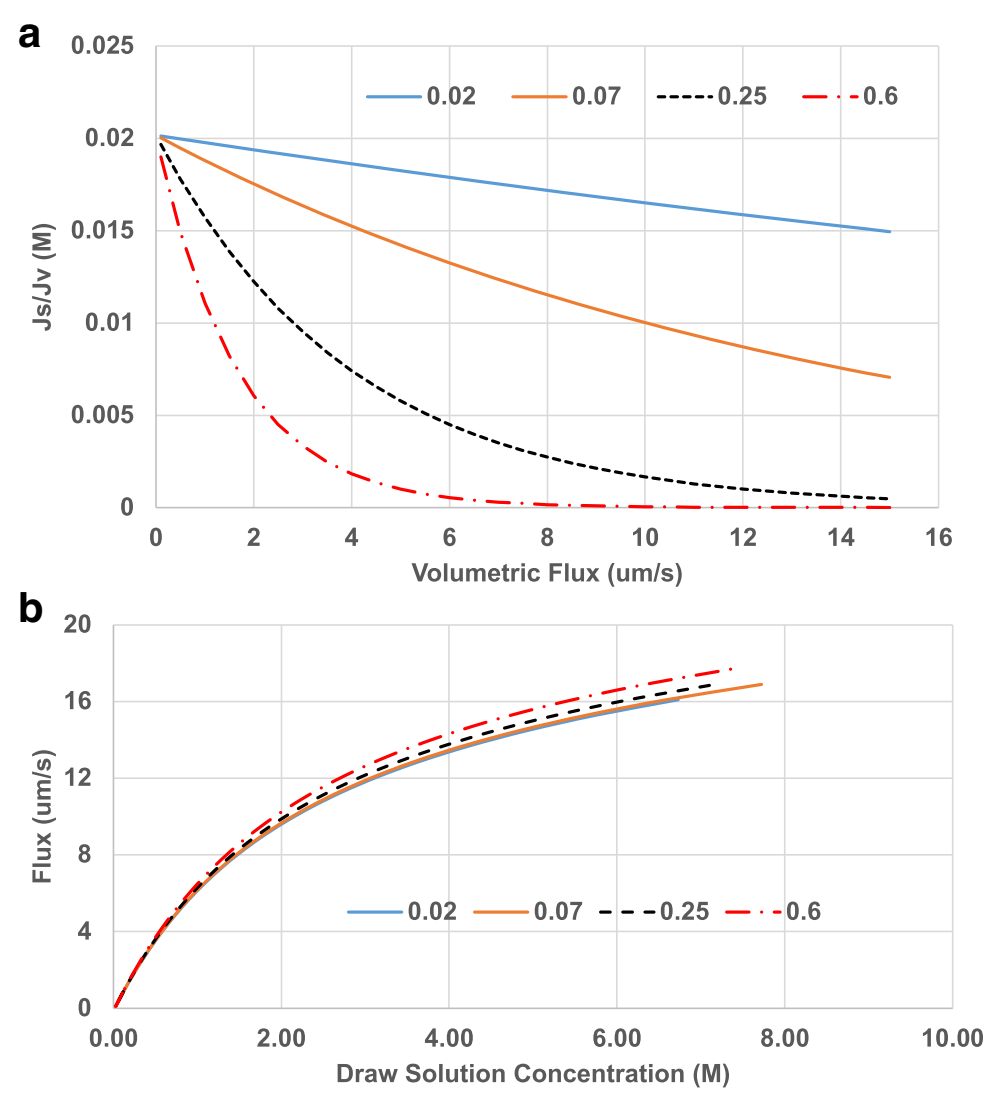

Fig. 5 Predicted influence of draw concentration, $c_{d}$, upon (a) flux ratio $J_{s} / J_{v}$ and (b) solvent flux, $J_{v}$, using Eq.8 for four selected values of the ' $a$ ' coefficient, namely $0.02,0.07,0.25$ and 0.6 . Standard conditions except $B=0.4 \mu \mathrm{m} \mathrm{s}^{-1}, \mathrm{~A}=2 \mu \mathrm{m} \mathrm{s}^{-1} \mathrm{MPa}^{-1}$

Previously it has been used to describe the transport across the active layer of a FO/PRO membrane [13]. A comparison with the standard two-parameter solutiondiffusion (S-D) model was made and little difference was found [12]. Having noted concerns regarding the S-K model, at least as it is applied to FO the scope of the paper has been extended to include a purely empirical equation. This equation (i) tends of the S-D model at low flux and (ii) $\left(\frac{J_{s}}{J_{v}}\right)$ declines with increasing $J_{v}$ but the ratio is never positive i.e. it tends to zero and does not transition into a regime of supposed co-current flow of solute and solvent.

$$
\left(-\frac{J_{s}}{J_{v}}\right)=\frac{B}{A \sigma \beta R T} \exp \left(-a J_{v}\right)
$$

where 'a' would be determined from experiments. Herein the concern is to establish the influence of 'a' upon the flux-draw concentration relationship.

\section{Methodology}

The results displayed in Figs. 2, 3, 4, and 5, are obtained by solving Eqs. 5 and 9 . The difference $c_{m}-c_{i}$ is eliminated by recognising (as in [8]) that the transmembrane solvent flux is also given by:

$$
J_{v}=\sigma A v R T\left(c_{m}-c_{i}\right)
$$

It will be readily appreciated that the four Eqs. $5 \mathrm{a}, \mathrm{b}, \mathrm{c}$ and 9 contain four unknowns: $\left(\frac{-J_{s}}{J_{v}}\right), c_{i}, c_{m}$ and either the flux $J_{v}$ (if $c_{d}$ is known) or $c_{d}$ if flux is specified. The procedure adopted was to specify values of the solvent flux, $J_{v}$, for fixed values of feed salinity, $c_{f}$, and the relevant membrane and system parameters. This enabled one to calculate the Peclet numbers. Then equating Eq. $5 \mathrm{a}$ and $5 \mathrm{~b}$, one can find $c_{i}$. As the difference $\left(c_{m}-c_{i}\right)$ can be calculated from Eq. 9 one then obtains the other boundary concentration, $c_{m}$. Also with a known value of $c_{i}$, the flux ratio, $\left(\frac{-J_{s}}{J_{v}}\right)$, can be found from Eq. 5b. Finally from Eq. 5 c, the draw solution concentration, $c_{d}$, is found.

\section{Results and discussion}

Unless indicated otherwise the parameters used are the standard conditions given in Table 1. Fig. 2 illustrates the influence of the draw concentration, $c_{d}$, upon solvent flux, $J_{v}$, for the solution-diffusion model and two versions of 
the Spiegler-Kedem model, the one introduced herein and the one given in [8]. This implementation of the S-K model to Forward Osmosis has the following equation for the barrier layer:

$$
\left(-\frac{J_{s}}{J_{v}}\right)=(1-\sigma) \cdot \frac{c_{m} \exp \left(-P e_{m}(1-\sigma)\right)-c_{i}}{1-\exp \left(-P e_{m}(1-\sigma)\right)}
$$

Figure 2 has used dashed lines for those part of the predicted $J_{v^{-}} c_{d}$, curves that correspond with predicted co-current flow of solute and solvent. This is counter to the experimentally observed reverse salt flux that is characteristic of forward osmosis (FO). Herein the possibility of co-current fluxes in FO is refuted. For the version of the S-K model introduced herein and the set of conditions indicated, the model is not valid for draw concentrations higher than $1 \mathrm{M}$. Overall this figure indicates that for physically realistic conditions there would essentially be no benefit from developing membranes that displayed a degree of 'leakiness' even if such a development were possible.

It has been suggested that if allowance is made for minor deviations from ideal semi-permeability then operation in an overlooked mode of "breakthrough" osmosis would be possible and importantly it would yield relatively large rates of osmosis [8]. Whilst this has been refuted for realistic conditions, it is of interest to check whether there are any conditions under which minor deviations from ideal semi-permeability would give higher fluxes. As shown by Eq. 5a a solute free feed $\left(c_{f}=0\right)$ has to have a positive value for the term $\left(-J_{s} / J_{v}\right)$ i.e. there is counter-current flow of solute and solvent. Thus it is of interest to compare the Spiegler-Kedem model with the solution-diffusion model and with the solution-diffusion model with $\mathrm{B}=0$ (labelled 'ideal') in order to understand their respective behaviours. As shown in Fig. 4, the use of the three parameter S-K model with $\sigma=0.99$ predicts fluxes that are intermediate between those of a standard solution-diffusion model and those of the solution-diffusion model with $\mathrm{B}=0$. Clearly it is beneficial to reduce reverse salt diffusion. In qualitative terms this is not a surprising result, but the relative importance in quantitative terms can be startling. From Eq. 5a and Eq. 5c the concentration difference across the active layer can be written as:

$$
\begin{aligned}
c_{m}-c_{i}= & c_{d} \exp \left(-P e_{b l}\right)-c_{f} \exp \left(P e_{s}\right)-\left(-\frac{J_{s}}{J_{v}}\right) \\
& \times\left[\exp \left(P e_{s}\right)-\exp \left(-P e_{b l}\right)\right]
\end{aligned}
$$

This equation clearly shows the important of solute diffusion, a matter which has been discuss in [14].

To conclude the exploration of the importance of the $\left(-\frac{J_{s}}{J_{v}}\right)$ term, the predictions given by Eq. 8 were analysed using standard conditions as given in Table 1 except for the 'B' parameter. As Eq. 8 hypothesises that the magnitude of $\left(-\frac{J_{s}}{I_{v}}\right)$ declines with increasing $J_{v}$ the initial value of 'B' was $0.4 \mu \mathrm{m} \mathrm{s}^{-1}$. If it were found that the ratio $\left(-\frac{J_{s}}{J_{v}}\right)$ declines with increasing solvent flux then 'a' would be determined from experiments. Herein the concern is to establish the influence of ' $a$ ' upon the flux-draw concentration relationship and this is illustrated in Fig. 5. It shows that whilst the term $\left(-\frac{J_{s}}{J_{v}}\right)$ can rapidly reduce to zero (but does not go negative) there is very little effect upon the flux-draw solution relationship for the realistic set of values used.

Finally, a remark is made regarding the omission of the pressure term from the volumetric flux equation (Eq. 1). The implicit assumption is that one can apply the maximum principle for pressure [16]. When this principle is valid, the maximum and minimum pressure values are located at the domain's boundary. Given that in FO the pressure can be taken to be the same at each boundary the application of this principle would imply that the pressure throughout the barrier layer is the same as that at the boundary. Strictly speaking, this has been assumed and has not been proven.

\section{Conclusions}

From the above theoretical analysis there is no reason to believe that it would be of any benefit to explore practically various degrees of deviation from ideal semi-permeability. Whether 3 parameter models are worth pursuing is an open question but with regard to the 3 parameter S-K model, it should be applied to FO and PRO with great prudence. That intriguing counter-intuitive outcomes can result from its application clearly indicates a need to

Table 1 Standard conditions for generation of flux-draw concentration curves

\begin{tabular}{llllll}
\hline Parameter & $\begin{array}{l}\text { Hydraulic } \\
\text { permeability }\end{array}$ & $\begin{array}{l}\text { Solute } \\
\text { permeability }\end{array}$ & $\begin{array}{l}\text { Reflection } \\
\text { coefficient }\end{array}$ & $\begin{array}{l}\text { Structural } \\
\text { parameter }\end{array}$ & $\begin{array}{l}\text { Draw side mass transfer } \\
\text { coefficient }\end{array}$ \\
\hline Symbol (units) & $\mathrm{A}\left(\mu \mathrm{m} \mathrm{s}^{-1} \mathrm{MPa}^{-1}\right)$ & $\mathrm{B}\left(\mu \mathrm{m} \mathrm{s}^{-1}\right)$ & $\sigma$ & $\mathrm{S}$ & $\mathrm{k}_{b /}\left(\mu \mathrm{m} \mathrm{s}^{-1}\right)$ \\
Value & Varied & 0.2 & 0.99 & 350 & 30 \\
Source / comment & Minimum as [14] & {$[14]$} & {$[8]$} & {$[14]$} & $\begin{array}{l}\text { About 4x greater than value } \\
\text { found for current modules [15] }\end{array}$ \\
\hline
\end{tabular}


rethink the formulation of the equations and the expressions for the coefficients especially when it is applied outside of the sphere of RO.

The possibility of different transport behaviours in $\mathrm{RO}$ versus FO has been debated from as early as 1976, when Loeb [17] mentioned the need for verifying if membrane water permeance $(\mathrm{A})$ was the same in $\mathrm{RO}$ and $\mathrm{PRO}$, and a more recent review reported that the ratio of $(\mathrm{A} / \mathrm{B})_{\mathrm{FO}}$ to $(\mathrm{A} / \mathrm{B})_{\mathrm{RO}}$, has been reported to be very different $[18]$.

\section{Nomenclature}

A 'A' parameter for water flux $\left(\mu \mathrm{m} \mathrm{s}^{-1} \mathrm{MPa}^{-1}\right)$

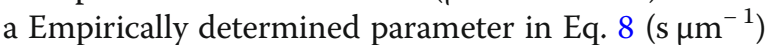

B 'B' parameter for salt flux $\left(\mu \mathrm{m} \mathrm{s}^{-1}\right)$

c solute concentration $\left(\mathrm{kg} \mathrm{m}^{-3}\right.$ or $\left.\mathrm{M}\right)$

$D$ diffusion coefficient $\left(\mathrm{m}^{2} \mathrm{~s}^{-1}\right)$

$k$ mass transfer coefficient $\left(\mu \mathrm{m} \mathrm{s}^{-1}\right)$

$J_{s}$ solute flux $\left(\mathrm{kg} \mathrm{m}^{-2} \mathrm{~s}^{-1}\right)$

$J_{v}$ volumetric flux $\left(\mu \mathrm{m} \mathrm{s}^{-1}\right.$ or $\left.\mathrm{m} \mathrm{s}^{-1}\right)$

$\mathrm{R}$ universal gas constant $\left(\mathrm{J} \mathrm{kg}^{-1} \mathrm{~K}^{-1}\right)$

$S$ structural parameter $(\mu \mathrm{m})$

T absolute temperature (K)

Pe boundary layer (modified) Peclet number

$\beta$ van 't Hoff factor

$\sigma$ solute reflection coefficient

$X$ hydraulic permeability

$\omega$ solute permeability

\section{Subscripts}

b bulk

bl boundary layer on draw side

d draw side (bulk)

$\mathrm{f}$ feed (bulk)

$i$ boundary between support layer and barrier layer

$\mathrm{m}$ surface of barrier layer on draw side

s support layer

$\mathrm{v}$ volumetric

\section{Abbreviations}

S-D: Solution Diffusion model; S-K: Spiegler-Kedem model; S-K-W: SpieglerKedem model; S-K-Y: Spiegler-Kedem model

\section{Acknowledgements}

For this published article, none.

\section{Funding}

The author is grateful to EPSRC and Durham University for GCRF Seedcorn funding.

\section{Availability of data and materials}

Not applicable; all data generated or analysed during this study are included in this published article.

\section{Authors' contributions}

Single-author paper. The author read and approved the final manuscript.

\section{Competing interests}

The author declares that he has no competing interests.

\section{Publisher's Note}

Springer Nature remains neutral with regard to jurisdictional claims in published maps and institutional affiliations.

Received: 8 January 2019 Accepted: 21 April 2019

Published online: 19 June 2019

\section{References}

1. Loeb S. Production of energy from concentrated brines by pressure retarded osmosis. I Preliminary technical and economic correlations. J Membr Sci. 1976;1:49-63.

2. Loeb S, Norman RS. Osmotic power plants. Science. 1975;189:654-5.

3. Lee KL, Baker R, Lonsdale H. Membranes for power generation by pressureretarded osmosis. J Membr Sci. 1981;8:141-71.

4. Loeb S. Large-scale power production by pressure-retarded osmosis using river water and sea water passing through spiral wound modules Desalination. 2002:143:115-22.

5. http://www.powermag.com/statkraft-shelves-osmotic-power-project/ Accessed 27 Oct 2017.

6. Straub AP, Deshmukh A, Elimelech M. Pressure-retarded osmosis for power generation from salinity gradients: is it viable? Energy Environ Sci. 2016:9:31-48.

7. Lin S, Straub AP, Elimelech M. Thermodynamic limits of extractable energy by pressure retarded osmosis. Energy Environ Sci. 2014;7:276-2714.

8. Yaroshchuk A. "Breakthrough" osmosis and unusually high power densities in pressure-retarded osmosis in non-ideally semi-permeable supported membranes. Sci Rep. 2017;7:45168. https://doi.org/10.1038/srep45168.

9. Wang J, et al. A critical review of transport through osmotic membranes. J Membr Sci. 2014;454:516-37.

10. Yaroshchuk AE. Osmosis and reverse osmosis in fine-porous charged diaphragms and membranes. Adv Colloid Interf Sci. 1995;60:1-93.

11. Geise GM, Freeman BD, Paul DR. Sodium chloride diffusion in sulfonated polymers for membrane applications. J Membr Sci. 2013;427:186-96.

12. Spiegler KS, Kedem O. Thermodynamics of hyperfiltration (reverse osmosis): criteria for efficient membranes. Desalination. 1966;1:311-26.

13. Attarde D, Jain M, Gupta SK. Modeling of a forward osmosis and a pressureretarded osmosis spiral wound module using the Spiegler-Kedem model and experimental validation. Sep Purif Technol. 2016;164:182-97.

14. Field RW, Wu JJ. On boundary layers and the attenuation of driving forces in forward osmosis and other membrane processes. Desalination. 2018:429:167-74.

15. Field RW, Siddiqui FA, Ang P, Wu JJ. Analysis of the influence of module construction upon forward osmosis performance. Desalination. 2018:431:151-6.

16. Golubkin VN, Kovalev VP, Sizykh GB. Maximum principle for pressure in ideal incompressible fluid flows. TsAGI Sci J. 2016:47:599-609.

17. Loeb S. Production of energy from concentrated brines by pressureretarded osmosis: I. preliminary technical and economic correlations. J Membr Sci. 1976;1:49-63.

18. Manickam SS, McCutcheon JR. Understanding mass transfer through asymmetric membranes during forward osmosis: a historical perspective and critical review on measuring structural parameter with semi-empirical models and characterization approaches. Desalination. 2017;421:110-26.

Ready to submit your research? Choose BMC and benefit from:

- fast, convenient online submission

- thorough peer review by experienced researchers in your field

- rapid publication on acceptance

- support for research data, including large and complex data types

- gold Open Access which fosters wider collaboration and increased citations

- maximum visibility for your research: over $100 \mathrm{M}$ website views per year

At $\mathrm{BMC}$, research is always in progress.

Learn more biomedcentral.com/submission 